\title{
Vegetation Database of Slovenia
}

\author{
Urban Šilc
}

\begin{abstract}
The Vegetation Database of Slovenia (GIVD ID EU-SI-001) is held at the Institute of Biology ZRC SAZU, Ljubljana, Slovenia. It contains all available published relevé material from the territory of Slovenia. All registered plant communities are covered. Relevés originate from published sources and grey literature (theses, survey reports). The database is used for archiving relevé material, for preparation of classifications and other analyses of vegetation of Slovenia and neighbouring countries.
\end{abstract}

Keywords: relevé; vegetation classification.

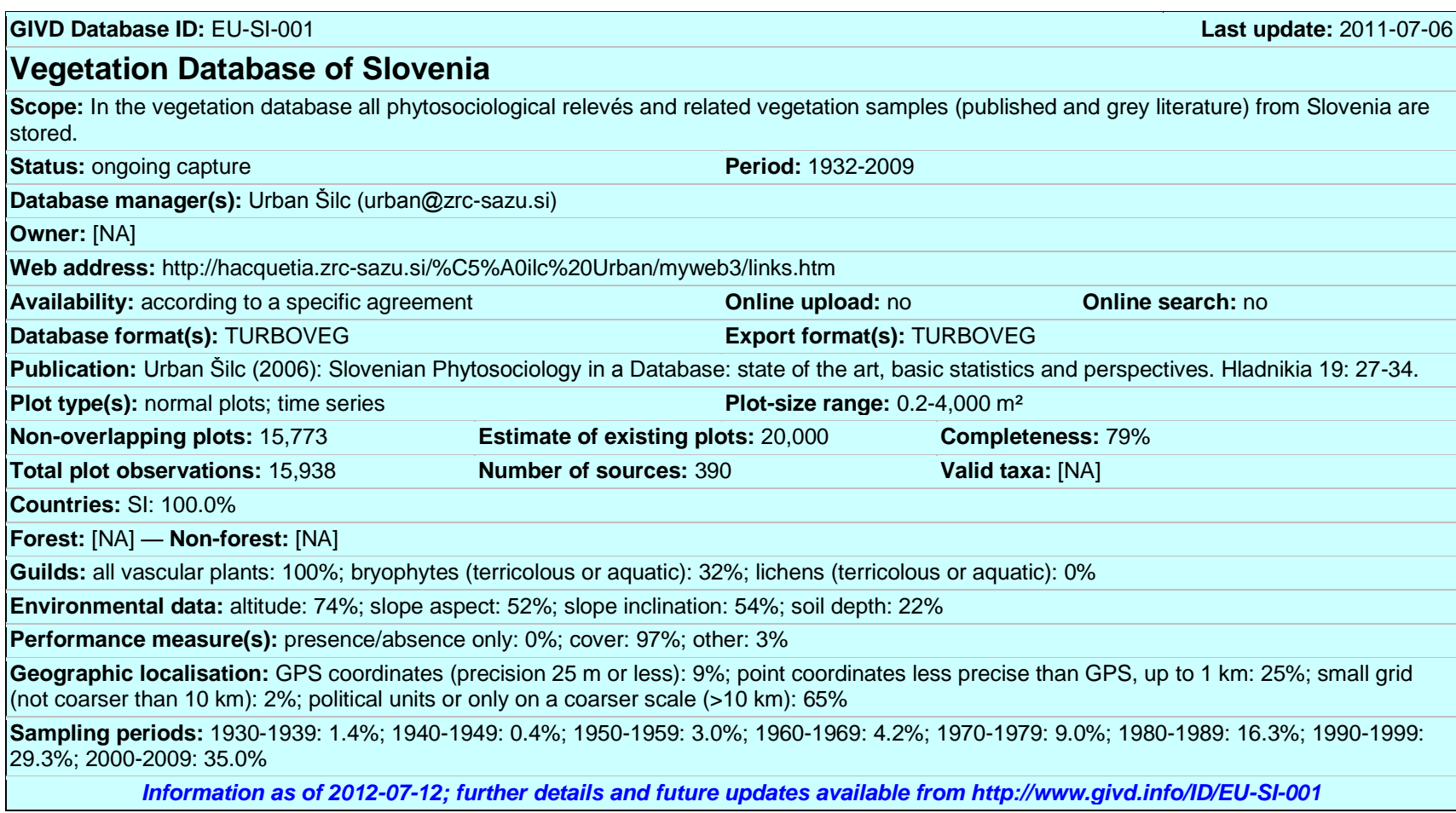

Urban Šilc (urban@zrc-sazu.si)

Institute of Biology, ZRC SAZU, Novi trg 2, 1000 Ljubljana, SLOVENIA 